\title{
A Palavra mágica e a palavra burguesa: notas sobre a linguagem no pensamento do jovem Walter Benjamin
}

\author{
ARTHUR DE A. LEÃO RODER *
}

RESUMO O presente artigo empreende uma leitura do enigmático ensaio do jovem Walter Benjamin, "Sobre a linguagem em geral e sobre a linguagem do homem” (1916), para expor uma compreensão a cerca da diferenciação produzida pelo autor entre as compreensões da linguagem pura, ou mágica, e linguagem burguesa. A segunda, sendo usada como imagem da língua enquanto meio de comunicação, aponta a um modelo de palavra entendida como "moeda de troca", isso é, como um instrumento de intersubjetividade e signo para referentes. Por outro lado, a concepção de Benjamin do caráter mágico da linguagem, ligada às suas interpretações do judaísmo, empreende uma reflexão contra a instrumentalidade da linguagem, seja ela conceitual ou referente. De fato, o jovem Benjamin extrai essa concepção das narrativas do Gênesis, mais precisamente do momento em que Adão herda o sopro divino (interpretado como a linguagem humana no ensaio) e o mundo para ser nomeado. Justamente enquanto nomeação, a linguagem será entendida como mágica na medida em que exprimirá tão somente sua comunicabilidade como imagem acústica, sem resto material, traçando com as coisas nomeadas - inanimadas ou animadas - não uma relação de referência, mas de comunidade ou acolhimento. Remete-se, por fim, ao Prefácio Crítico Epistemológico de sua tese de habilitação (Sobre a origem do drama barroco alemão, 1925), texto que recupera e desenvolve, admitidamente, as teses apresentadas no ensaio de juventude, aplicando-as ao contexto epistemológico da crítica de arte. Procura-se, a partir desse ensaio, sugerir um desdobramento dessa diferenciação juvenil em suas fases mais maduras, notadamente as noções de tempo extensivo e intensivo, distinção que permite pensar a relação entre história, ideia e linguagem no pensamento de Benjamin como um todo.

PALAVRAS-chaVe Filosofia Contemporânea Continental; BENJAMIN, Walter; Linguagem e Teoria das Ideias.

* Mestrando PPGF - UFRJ

Bolsista CAPES 
REDIGIDO EM 1916, o ensaio é primeiramente dirigido por Benjamin como anexo de uma carta em resposta ao amigo e teólogo Gershom Scholem. Falando sobre o que ainda é um "pequeno tratado", Benjamin se refere ao ensaio como uma tentativa de “desembaraçar [démêler] para mim mesmo a essência da linguagem e isso, na medida em que eu pretendo alguma coisa, em referência imanente ao judaísmo e em referência explícita ao capítulo primeiro do Gênesis ${ }^{1 "}$. Efetivamente, Benjamin empreenderá no seu ensaio uma leitura do Gênesis (mais precisamente os capítulos de 1 a 3, que dão relato mítico, respectivamente, da criação do mundo, da criação do homem e da Queda), não porque a reconhece religiosamente como a revelação da verdade, como ele próprio diz ${ }^{2}$, mas porque as Escrituras correspondem à exigência “de pressupor a língua como uma realidade última, inexplicável e mística que só pode ser considerada em seu desenvolvimento 3". Portanto, Benjamin parte do mistério da linguagem, o que não significa um questionamento sobre o que fundamenta a linguagem. Muito pelo contrário, calcada na imagem do Verbo divino, a linguagem é aquilo mesmo que não apela por explicação ou esclarecimento. A pergunta quid juris? (“com que direito?”, a mesma pergunta com que Kant inaugura a mais comentada das seções da Crítica da Razão Pura, apelidada de Dedução transcendental) é inaplicável à língua: Benjamin manifestamente empreende suas reflexões a partir do judaísmo para que possa escapar da relação "racionalizada” (ou “mediada”) com o seu objeto. Nessa leitura mística, a língua deve exceder, assim, toda regra ou toda tentativa de apropriação racional em conceitos. Sua verdade é a pura e simples verdade do fato de que há linguagem.

Logo no título, o ensaio de Benjamin já anuncia uma distinção muito original em termos da tradição filosófica ocidental (majoritariamente helênica): Sobre a linguagem em geral e sobre a linguagem dos homens já dá a antever a expansão radical da possibilidade da linguagem para qualquer domínio, o que de fato é um aproveitamento da tese religiosa segundo a qual o mundo é criado imediatamente do Verbo divino. Em outras

\footnotetext{
1 BENJAMIN, 1979, p.119.

2 Idem, ibidem, p.119.

3 Idem, ibidem, p.119.
} 
palavras, tudo aquilo que existe, participaria de uma forma ou de outra na expressão no linguagem. Nesses termos, Benjamin diferencia ligeiramente humano e linguagem: a segunda deixa de ser uma noção estritamente antropológica ou cultural, e ultrapassa o domínio dos seres humanos, ou de cada tronco linguístico particular, para sofrer uma generalização radical. “... a existência de linguagem estende-se não apenas a todos os domínios de manifestação do espírito humano, ao qual, num sentido ou em outro, a língua sempre pertence, mas a absolutamente tudo 4". E somando a isso: “o que não conhecemos fora da linguagem humana é uma linguagem nomeadora5". Entretanto, por mais que a linguagem se estenda a toda a realidade, ainda há uma peculiaridade entre a língua sonora ou falada (isso é, a humana) e a língua muda e material da natureza. No entanto, ainda que guarde um privilégio, a posição legada ao homem é destituída do seu lugar originário na medida em que ele não é mais tomado como o sujeito da fala, presente a si por excelência - como mostraremos, essa perspectiva é justa aquela que marcará a compreensão burguesa da língua. A linguagem, para o autor, será como uma porta para o infinito, isso é, como um movimento de ultrapassagem da finitude e a possibilidade de uma reintegração da experiência da realidade, como já colocou Katia Muricy ${ }^{6}$. Em outras palavras, o homem não é, no esquema desenhado pelo jovem Benjamin, nem a origem nem o fim do movimento linguístico que compõe o mundo, mas tão somente um ponto intermediário. Portanto, apenas uma passagem, ainda que nodal e necessária, apenas uma passagem dentre outras.

Para o jovem Benjamin, essa imensidão da linguagem não é somente uma metáfora: ela quer expressar o fato de que tudo o que existe se expressa. Ora, é apenas na medida em que Benjamin escusa a linguagem de sua noção significativa (mediática, instrumental, burguesa), que se pode pensar no deslocamento do fato da linguagem para os seres como um todo. Desse modo, o movimento total da linguagem apresentará uma diversidade de linguagens ou de línguas, humanas e não humanas. É na medida em que Benjamin emancipa essa noção, religiosa, de linguagem da sua servidão e instrumentalidade ao ser humano e à sua cultura, que ela passa a ser pensada para além do elemento humano, o que refletiria inclusive como expropriação da definição do

\footnotetext{
4 BENJAMIN, 2013b, pp.50-51.

5 Idem, ibidem. p.54.

6 MURICY, 1999, p.81.
} 
homem como zoon logon (expressão de Aristóteles que caracteriza o humano como o animal dotado de linguagem, logos, ou ainda o animal racional), dado que a linguagem não mais permanece como sua propriedade particular, privada dos outros entes do mundo, e do mundo ele mesmo.

Nesse ritmo, poder-se-ia apontar que a teoria desse ensaio, no que ele pretende "desembaraçar" a teoria da linguagem, não se pretende uma espécie de "crítica da linguagem pura" - isso é, não se pretende uma discriminação do que é essencial ou propriamente linguístico do que é inessencial e alheio ao domínio da linguagem. A manobra de Benjamin nesse ensaio não é nem mesmo a delimitação do âmbito em que a linguagem poderia vigorar por oposição a um âmbito negativo de indizibilidade, um fora-da-linguagem. Na verdade, trata-se muito mais de remover os critérios ou medidas externas da linguagem: enquanto grande exceção, a linguagem não conheceria fundamentos que não ela mesma. Benjamin, nesse ensaio, aponta para uma dimensão infinita da linguagem justamente no que a linguagem é imensa: isso é, imensurável, exceção de toda medida ou proporção externa. Traçando uma dialética peculiar, Benjamin produz uma diferenciação entre as essências espiritual e linguística de cada coisa para que descreva como a expressão não se dá através da língua, mas na língua, imediatamente. Não atribuindo identidade entre espírito (comunicabilidade) e língua (comunicação), mas uma diferença que pode se dar em maior ou em menor grau, coloca-se um hiato entre expressividade (espírito) e expressão (língua, ato de comunicação propriamente dito que não necessariamente se dá por palavras, mas também de modo mudo). A relação imediata parte dessa diferenciação, do hiato variável entre a comunicabilidade e a comunicação, e não significa uma identidade entre a expressão e a coisa. Portanto, é essa diferença que permitirá a sua relação imediata, ainda que nas coisas materiais produza um resto que não é senão a própria materialidade dessa coisa. Conclui-se disso que a relação de imediatidade não recorre a uma mera equação entre os extremos, mas muito mais numa relação de preenchimento $^{7}$.

7 “A essência espiritual comunica-se em uma língua e não através de uma língua, isso quer dizer que, vista do exterior, ela, a essência espiritual, não é idêntica à essência linguística. A essência espiritual só é idêntica à essência linguística na medida em que é comunicável. O que é comunicável em uma essência espiritual é sua essência linguística. Portanto, a linguagem comunica, a cada vez, a respectiva essência linguística das coisas; mas sua essência espiritual só é comunicada na medida em que se encontra imediatamente encerrada em sua essência linguística, na medida em que ela seja comunicável”. (BENJAMIN, 2013b, p.52). 
Há algo que não se encerra na essência linguística: um espaço branco entre a língua (o Medium) e o espírito da coisa, como um traço que se desenha sobre uma folha de papel e resguarda cuidadosamente o branco que o determinará, aquilo mesmo que abre e fecha a comunicabilidade sem ser, no entanto, comunicável. O segredo de fato da linguagem, seu fundamento.

Prosseguindo o desenvolvimento do texto de Benjamin, “esse elemento comunicável é a linguagem mesma sem mediações ${ }^{8}$, pois a coisa, no que é exprimível, não se expressa através de sua essência linguística ou através de sua linguagem, mas nela mesma, como dirá Benjamin. “Aquilo que é comunicável em uma essência espiritual é aquilo no que ela se comunica; o que que dizer que toda língua se comunica a si mesma. Ou melhor: toda língua se comunica em si mesma; ele é, no sentido mais puro, o meio [Medium] da comunicação" ". Prolongando:

A característica própria do meio [Medium], isto é, a imediaticidade de toda comunicação espiritual, é o problema fundamental da teoria da linguagem, e, se quisermos chamar de mágica essa imediatidade, então o problema originário da linguagem será a sua magia. Ao mesmo tempo, falar da magia da linguagem significa remeter a outro aspecto: a seu caráter infinito. Este é condicionado por seu caráter imediato. Pois precisamente porque nada se comunica através da língua, aquilo que se comunica na língua não pode ser limitado nem medido do exterior, e por isso em cada língua reside sua incomensurabilidade, e única em seu gênero, infinitude. É a sua essência linguística, e não seus conteúdos verbais, que define o seu limite ${ }^{10}$.

As coisas não são objetos ou referentes da língua (como seria o caso da língua compreendia segundo sua funcionalidade significante), mas elas expressam sua própria linguagem enquanto a expressão de suas essências linguísticas - não sendo jamais representadas pela língua, nem mesmo significadas, uma coisa se comunica na medida mesma em que habita imediatamente sua expressão. Ora, cada língua é infinita: cada língua não se deixa tomar por qualquer critério externo. A infinitude da língua é, portanto, única em seu gênero, pois a essência linguística não se dá segundo qualquer estrutura transcendental ou genérica, isso é, não se dá subsumida a qualquer aspecto

8 Idem, ibidem, p.53.

9 Idem, ibidem, p.53.

$10 \mathrm{Ib} . \mathrm{pp} \cdot 53-54$. 
que a fundamente. Se toda língua é uma expressão imediata de si mesmo, logo, cada língua é ela mesma seu único critério de decodificação ou legibilidade possível. O Medium dá a ele mesmo seus próprios limites, seu próprio fundamento, e é autorreferente: a teoria esboçada por Benjamin nega a necessidade de a expressão exprimir-se através de um tropos hipostasiado, externo ao seu acontecimento singular, não partindo senão de sua própria peculiaridade, de seu ser língua. A linguagem, na teoria desenvolvida por Benjamin nesse ensaio, não é um dizer algo sobre algo (legein ti kata tinos), não se articula em significantes e significados e, portanto, não serve ao suposto falante como um meio [Mittel] para fins.

É na discussão a cerca da linguagem humana que a distinção entre imediatidade e mediação alcança um certo fim pretendido por Benjamin: separar a teoria da linguagem proposta no ensaio daquela que o próprio autor escarnece como a "concepção burguesa da língua”. Benjamin, então na discussão da linguagem humana, elege como a porta de entrada um elemento muito preciso, a saber, o nome (tanto o nome comum das coisas em geral, como o nome próprio do ser humano), palavra articulada em sons discretos, puro meio incorpóreo e, por isso, privilégio da língua humana em relação às línguas mudas da natureza, marcadas ainda pelo resto material. Considerando o projeto de Benjamin como um esforço para se pensar contra e além da linguagem representativa e referencial, pode-se perguntar o porquê dessa escolha pela função da linguagem que, segundo as teorias clássicas da significação, seria a própria forma da referência na linguagem, podendo ser vista, dentro de outras terias, como o maior exemplo do uso da língua como mittel, isso é, como a sua função significativa apesar de contraposta à realidade. Não se trata aqui, entretanto, de uma problematização ou limitação dessa teoria. Muito antes, é essencial, no que toca o deslocamento engendrado pela visão de Benjamin, que o nome ou a palavra seja o objeto eleito como paradigma da língua dos homens. Ora, trata-se mesmo de uma teoria que leia de outra forma a relação que a linguagem possui com o mundo - é essencial para sua teoria a relação da linguagem com a matéria (e por isso pensar o nome dado às coisas após a herança da Criação) e a relação da linguagem com a singularidade de cada indivíduo, e consequentemente sua história (e por isso pensar o nome dado entre as gerações).

De todo modo, a partir dessa reflexão, Benjamin pressupõe a antítese à sua teoria nessa imagem da língua burguesa. A pista deixada por Benjamin no ensaio de 1916 envolve o seu uso das conjunções em [in] e através de [durch], o primeiro remetendo 
a imediatidade e o segundo à mediação pela palavra (seu uso instrumental). Isso é, "uma concepção de linguagem [humana] essencialmente falsa ${ }^{11 " ~-~ n a ̃ o ~ u m a ~ t e o r i a ~}$ que comunica o falso, mas uma teoria que entende a linguagem humana fora do seu caráter imediato, reproduzindo um modelo de expressão conforme um esquema representativo, ou referencial, da palavra: a comunicação através do nome. Portanto, qualquer teoria que reproduza como essência da linguagem a significação e a possibilidade disjuntiva de enunciar, propositiva ou articuladamente, tanto o verdadeiro quanto o falso, enquanto essas noções são entendidas como objetos lógicos correspondentes ao valor de cada proposição. Nessa visão, a palavra nada mais seria do que uma moeda de troca, verdadeira ou falsa, de valor positivo ou negativo, para referir-se a entes exteriores de modo, idealmente, inequívoco. No fundo, esse esquema prevê sua serventia na construção de uma economia em que a língua é emprega para normatizar um mundo alheio a ela própria. A palavra é, pois, cunhada tendo em vista valer por outro, logo, ela é inflacionada pois tem essencialmente seu valor perdido, trocado, desapropriado e mesmo roubado ou alienado. Ora, a palavra aí se torna, sobretudo, um instrumento, um meio para fins [Mittel] e não um meio imediatamente expresso em si [Medium]. Cunhando o nome como moeda, a concepção burguesa da linguagem dá margem somente a uma comunidade entre os homens pautada economicamente na troca intersubjetiva: a sua comunicação está aí como um valor, sempre de troca, e essencialmente inflacionado, pois perde seu caráter mágico e infinito.

Em contrapartida, o nome em Benjamin, muito antes de ser aquilo que vale por outro no discurso, será a própria comunicação da comunicabilidade da linguagem e o elemento no qual a linguagem se realiza em sua totalidade como Medium, tal como desenvolvemos. Primeiramente, a teoria benjaminiana conservará ao nome o seu papel de relação com a realidade, mas imprimirá nela um deslocamento radical em relação às teorias da significação. O ato da nomeação [Namensprache], seja ele um nome comum ou nome próprio, não comunica a coisa que ele pretenderia comunicar através de sua expressão, mas tão somente a língua de forma absoluta. Nesse sentido, o nome será o ponto de condensação máxima da linguagem - o seu limite e o seu extremo, pois é a nomeação que dará mostras não do uso referencial da língua, mas da essência mesma da língua como sua magia ou imediatidade. Nomear, em sua

11 Idem, ibidem, p.55. 
forma verbal infinita, talvez seja aqui a palavra mais adequada para se entender a linguagem humana no ensaio de Benjamin: pois se trata do que o ato de nomeação produz imediatamente no homem e no mundo. Deve-se certamente entender o nomear aqui não como a etiquetagem de uma coisa, mas o seu acolhimento na linguagem, de modo que o ato de nomear não seja visto na criação idiomática de um significante para a coisa; mas sim na tradução em nome daquilo que não tem nome, ou ao menos daquilo que não se expressa em uma imagem acústica, mas apenas por imagens de outras ordens. A nomeação produz, pois, seu efeito como uma tradução e, por isso mais como um "pôr-em-relação", do que uma representação através de um elemento heterogêneo, com fins instrumentais. O sentido da nomeação, em Benjamin, mescla expressão [Ausdruck] e interpelação [Andruck]: ao mesmo tempo ele é a mais intensa e mais extensa manifestação da linguagem.

Contudo, o nome não é somente a última exclamação; é também a verdadeira interpelação da linguagem. Com isso, aparece no nome a lei essencial da linguagem, segundo a qual expressar-se a si mesmo e interpelar todas as outras coisas são um só movimento. A linguagem - e nela, uma essência espiritual - não se exprime de modo puro senão quando ela fala no nome, quer dizer, na nomeação universal. Assim, no nome culminam a totalidade intensiva da língua como essência universalmente comunicável, e a totalidade extensiva da língua como essência universalmente comunicante (que nomeia). A linguagem será imperfeita em sua essência comunicante, em sua universalidade, quando a essência espiritual, que fala a partir dela, não for, em toda a sua estrutura, algo linguístico, isto é, algo comunicável. Somente o homem possui a linguagem perfeita do ponto de vista da universalidade e da intensidade ${ }^{12}$.

Não obstante o ser humano não ser a única existência dotada de expressão, ele ainda será um ponto nodal no caminho que a linguagem deve percorrer para atravessar a realidade como um todo, uma vez que o ser humano, para Benjamin, será o destinatário das diversas formas de essências linguísticas não no sentido em que tudo aí está para ele, mas no sentido em que o ser humano se coloca como um receptor dessa diversidade de línguas, e mesmo como uma passagem intermediária em direção ao “centro inacessível desse movimento”, nas palavras de Katia Muricy. Enquanto liame de um percurso maior, o homem é por isso muito mais passivo do que ativo. Ora,

12 Idem, ibidem, p.57.

13 Vide nota 6. 
o ato de nomear, por mais que não se dirija à coisa significativamente, é muito mais uma reação à expressão que parte da coisa muda. Benjamin falará de uma receptividade ativa para a nomeação: o ser humano conhece na medida em que recebe das coisas sua língua afônica - trata-se, antes, de uma reação ou uma ação que consiste em receber, acolher e restituí-la em sons, ou traduzi-la. É nessa esteira que Benjamin se apropria da narrativa mítica do Gênesis, no momento em que Deus sopra a linguagem a Adão ${ }^{14}$ para que ele receba a Criação e a nomeie, criando a partir do Verbo divino uma relação, secundária, de conhecimento com a natureza. Deus gratifica Adão com o dom de manter uma comunidade com o seu Verbo e, consequentemente, com a língua muda e enlutada da natureza. A teoria da linguagem de Benjamin dispensa, portanto, o lugar do sujeito como fundador do sentido ou como sujeito de intenções essenciais à fala: o homem é uma passagem no movimento da língua. Para essa teoria não há a mínima necessidade de um observador armado de um aparato epistêmico para que se dê a inteligibilidade: antes, as coisas se expressam em sua própria língua. Enquanto receptor, o homem então responde a elas em sua própria língua, fazendo seu papel de meio do caminho da linguagem.

Deslocando a imagem do que seria o humano no seio de uma discussão sobre a natureza da linguagem, e mesmo da relação que a linguagem trava com o mundo, Benjamin na verdade constrói um conceito de linguagem com pretensões ontológicas muito peculiares (ou talvez com nenhuma pretensão ontológica, pois a única pretensão de ser que ela possuirá nesse registro desloca todo esquema tradicional da ontologia). Antes de possuir um ser linguagem em particular, antes de pretender circunscrever um campo de possibilidades que dariam conta da propriedade do que é ser essa linguagem pura, o único ser ao qual essa linguagem ainda poderia pretender é um ser absolutamente geral. Não se quer com isso, todavia, travar alguma relação entre a linguagem benjaminiana, enquanto esse fundamento radical, e o sentido do ser tal como é caracterizado em Ser e tempo de Martin Heidegger ${ }^{15}$. Muito antes, é algo oposto que o texto de Benjamin dá a pensar. Recuperando a caracterização da linguagem pelo autor como aquilo em que se somam a máxima exclamação [Ausdruck] e a máxima interpelação [Andruck], é visível como esse conceito (a nomeação no caso,

14 Genesis 2.

15 HEIDEGGER, 2015, pp.37-51. 
die Namensprache) é ao mesmo tempo apontado como o ápice de todo um movimento de identificação - a saber, a linguagem como comunicabilidade pura. O mais interessante, entretanto, é que nesse caso a máxima exclamação (a máxima comunicação da própria comunicabilidade) vem acompanhada necessariamente da máxima interpelação de todas as outras coisas, isso é, do máximo direcionamento ao outro. Sendo a interpelação exatamente isso, a todos os outros, então o máximo de ser linguagem, na teoria de Benjamin, no mesmo gesto em que ergue sua identidade na nomeação, é ser Outro. A essência da linguagem é exclamar-se e interpelar a tudo: mas ambos os momentos não devem distinguir-se, qual duas faces de uma moeda, mas sim terem lugar ambas em um único gesto. Nessa teoria de Benjamin, a linguagem é tão mais ela mesma quanto mais ela é o outro, quanto mais ela pode acolher ou traduzir. Não se trata de sintetizar um terceiro momento posterior à contradição entre exclamação e interpelação, mas de suspendê-los em sua contradição. A linguagem segue, portanto, o paradigma do acolhimento do mundo para talvez até mesmo confundir-se com ele, pois não persegue uma distinção radical ou ontológica com o outro, mas uma identificação com a alteridade.

Enquanto o ensaio de 1916, em sua confecção, não passou de um esboço privado de sistema, como dito, enviado em carta ao amigo Gershom Scholem, é no Prefácio à sua tese de habilitação, Origem do drama barroco alemão ${ }^{16}$ (1925), que Benjamin amadurece a sua concepção de linguagem no contexto da epistemologia à crítica de arte. O que quer dizer que a noção de ideia retomará em alguma medida aquela forma de comunicação pura do Medium da linguagem, antes entendida na nomeação. Muito antes de meramente aplicar sua teoria da linguagem em matéria de conhecimento, Benjamin submete o conhecimento à linguagem: efetivamente, para o autor, ideia é linguagem. Ideia, no pensamento de Benjamin, deverá, analogamente ao caso do nome, remeter a uma concepção de inteligibilidade que não se fundamenta em nenhuma contradição entre as ordens de ideia e fenômeno, nem mesmo entre sujeito e objeto. Como a linguagem, a ideia será expropriada da existência privada e mental, que teria muito mais a ver com a noção de conceito, diferenciada pelo autor da dimensão ideal. Efetivamente, Benjamin põe o conceito naquela dimensão da linguagem burguesa ou instrumental, que visaria não a espécie de objetividade que sua teoria busca, mas

16 BENJAMIN, 2013a, pp.15-47. 
procuraria tão somente a captura do fenômeno, ou mesmo como um princípio de organização, esquematização, entre outros.

Como escreve Benjamin no Prefácio, "a verdade é a morte da intenção": portanto, a teoria das ideias benjaminiana não remeterá a uma experiência subjetiva, particular ao gênio do conhecimento. Antes, o saber [Wissen] será entendido como uma contemplação, objetiva, pois estará deslocado da subjetividade teórica e não comporá uma cópia ou reprodução daquilo que é contemplado. Não representativa, a ideia é uma apresentaçã $0^{17}$ da verdade. A ideia, então, enquanto existência real e objetiva, não é vertical ao singular, ao contrário do que seria para conceitos da ordem de gêneros literários. "Estas ideias não são a quintessência de um conjunto de regras, mas antes figuras que, na sua densidade e no seu grau de realidade, são equivalentes a qualquer drama singular, não sendo com ele comensuráveis ${ }^{18}$ ". Dir-se-ia, a ideia não é para Benjamin um molde, não é o conjunto das condições de repetibilidade de um certo universal no particular, tampouco a imagem normatizada ou normal dos fenômenos. Enquanto a comunicação no nome no ensaio de 1916 era entendida como da ordem da imediatidade e da tradução, a inteligibilidade dos particulares dada pela ideia será, de certo modo, no Prefácio, uma objetividade oblíqua. Oblíqua porque ela também não se sustenta num esquema hipostasiado do fenômeno, mas guarda com ele uma certa adjacência epistêmica (não hierárquica), ainda que incomensurável em qualidade.

A ilustração de sua noção de ideia é dada por Benjamin em duas imagens, portas de entrada mui profícuas para sua investigação: (i) o mosaico e (ii) a constelação - isso é, a ideia, a todo inteligível, deveria relacionar-se com os fenômenos tal como a imagem do mosaico é composta por cada imagem dos fragmentos particulares: Ideia e mosaico,

ambos se compõem de elementos singulares e diferentes [...]. O valor dos fragmentos de pensamento é tanto mais decisivo quanto menos imediata é a sua

17 Nesse momento do texto, Benjamin faz uso da palavra alemã Darstellung, preterindo Vorstellung, para caracterizá-la, o que pode ser entendido como um eco daquele mesmo gesto da diferenciação pelas preposição em [in] e através de [durch]. Ou seja, gesto de diferenciar sua teoria de outra que proporia o conhecimento como cópia, como a constituição de um intermediário instrumental como conhecimento, ao invés de preferir uma relação de imediatidade com o Medium.

18 BENJAMIN, 2013a, p.32-33. 
relação com a concepção de fundo, e desse valor depende o fulgor da representação, na mesma medida em que o do mosaico depende da pasta de vidro ${ }^{19}$.

A metáfora da constelação, por sua vez, aponta para o fato de que, em Benjamin, na ideia, os fenômenos estão ao mesmo tempo “dispersos e salvos ${ }^{20}$ ”. Em outras palavras, a ideia não reuniria para dominar, mas para dispor e configurar uma imagem dos particulares sem que seja perdida a particularidade de cada um - em uma palavra, para acolher, segundo mesmo uma imagem trazida por Benjamin no texto do Prefácio, as Mães fáusticas de Goethe ${ }^{21}$. Em suma, o saber não tratará, para Benjamin, de uma homogeneização dos fenômenos como repetição de um mesmo, mas a algo outro. É nesse sentido, então, que Ideia e Nome andarão juntos:

A estrutura da verdade exige, assim, um modo de ser que, na sua ausência de intenção, se aproxima do modo de ser simples das coisas, mas lhes é superior pela sua consistência e permanência. A verdade não consiste num intencionar que encontraria na empiria a sua determinação, mas na força [Gewalt] que marca a própria essência dessa empiria. O ser livre de toda fenomenalidade, e único detentor dessa força, é o ser do nome. É ele que determina o modo como são dadas as ideias. E estas dão-se, não tanto numa língua primordial, mas antes numa percepção primordial em que as palavras ainda não perderam a aura [Adel] da sua capacidade de nomear em favor de um significado cognitivo ${ }^{22}$.

Objetiva como a linguagem, isso é, dissociada da existência puramente mental de uma representação subjetiva, e como um esboço [Entwurf] da descrição de mundo, o ser da ideia é o mesmo que o ser das coisas, o que significa, na esteira do ensaio de 1916, que o ser da língua humana não se sobrepõe hierarquicamente ao ser dos fenômenos que ela nomeia, e não visa transcende-los em forma: tanto quanto a nomeação conjuga duas imagens, uma acústica e outra material, a ideia está no mundo não subjetivamente, mas objetivamente. Atribuir realidade às ideias, gesto retomado de Platão, representará para Benjamin pensar o conhecimento na linguagem, fundado no Medium e expropriado da intencionalidade ou daquela economia intersubjetiva do ser

19 Idem, ibidem, p.17.

20 Idem, ibidem, p.23.

21 As ideias - na formulação de Goethe: os ideais - são as Mães fáusticas. Permanecem obscuras se os fenômenos não se reconhecerem nelas e não se juntarem a sua volta. (BENJAMIN, 2013a, p.23)

22 Idem, ibidem, p.24. 
humano: jamais como uma restituição significante, mas como tradução e acolhimento de extremos.

Entretanto, Benjamin efetivamente mobiliza a sua noção de ideia em torno de um caráter virtual. O que o separa dos sistemas idealistas que o próprio autor cita (Platão, Leibniz e Hegel: que guardam em comum serem grandes sistemas idealistas e metafísicos da tradição filosófica) será a desvinculação da virtualidade da necessidade da transcendência - a ideia é virtual em relação ao fenômeno, tanto como o nome é virtual em relação aos nomeados. Todavia, de modo algum eles abrem um estrato heterogêneo, um outro mundo como mundo inteligível; antes, preenchem o mesmo espaço, permeiam-se mesmo que virtualmente. Se quisermos comparar, então, a ideia em Benjamin e em Platão, rememorando as três distinções feitas no Timeu²3 (a Ideia ou Forma espelhada na figura do pai; o sensível como o filho e o espaço onde a relação entre eles acontece, ou tem lugar [Khôra], como a mãe), seria necessário dizer que, em Benjamin, a figura do pai e a da mãe se confundem uma com a outra. Como virtualidade sem transcendência, sua ideia não é fálica (pois não é uma norma ou um conceito hereditário), em uma palavra, não é vertical. Muito pelo contrário: tanto quanto as imagens do mosaico e a da constelação não acontecem desvinculadas de cada fragmento ou de cada pequeno ponto de luz, a ideia, enquanto linguagem - e nisso lembramos do nome que acolhe no som o nomeado mudo -, é imediatamente o espaço em que o fenômeno tem lugar. Ela possui o mesmo ser dos fenômenos, mas está separada deles por sua “consistência e permanência ${ }^{24 "}$. Benjamin ainda mobiliza uma noção de eternidade da ideia, pondo em jogo, então, a sua realidade histórica. De todo modo, essa noção benjaminiana de eternidade deve ser pensada para desvincular a linguagem da mera imanência: de certo modo, a ideia e a linguagem são menos que imanentes. Ainda no Prefácio, Benjamin aproxima a contemplação da ideia da rememoração, pondo-a em paralelo à anamnese platônica. "A percepção original das palavras 25", isso é, da língua em seu aspecto adâmico. Aproximando, assim, sua noção de ideia de uma categoria histórica, Benjamin a diferenciará, no entanto, de qualquer aspecto

23 PLATÃO, 2011, pp.69-211.

24 BENJAMIN, 2013a, p.24.

25 Idem, ibidem, p.25. 
genético, o que a afasta um pouco mais da Ideia platônica na figura do pai fálico e fertilizante, que inauguraria uma transmissão causal e hereditária como repetição.

Origem [Ursprung] não designa o processo de devir de algo que nasceu, mas antes aquilo que emerge do processo de devir e desaparecer [dir-se-ia, de tornar-se e tornar ao nada]. A origem insere-se no fluxo do devir como um redemoinho que arrasta no seu movimento o seu material produzido no processo de gênese. O que é próprio da origem nunca se dá a ver no plano do factual, cru e manifesto. O seu ritmo só se revela a um ponto de vista duplo, que o reconhece, por um lado como restauração e reconstituição, e por outro como algo de incompleto e inacabado ${ }^{26}$.

Oblíqua, a ideia apela a um ponto de vista duplo, a uma dialética peculiar ligada à "pré e pós-história ${ }^{27 ”}$ dos fatos sem se destacar deles. Em outros termos, como dirá Benjamin, "a pré e pós-história de tais seres essenciais, testemunho da sua salvação ou reunião na coutada do mundo das ideias, não é história pura, mas natural ${ }^{28 ”}$. A imagem da história natural, em Benjamin, é justamente o que o permite traçar a eternidade da sua concepção de ideia como linguagem. Benjamin assim aproxima sua concepção de vida natural a sua concepção da história em outra consistência: não sua transmissão genética, mas aquela dimensão de irrupção e ruptura que acontecem nos limites obscuros da história dos fenômenos (no caso do Prefácio, as obras de arte). Enquanto aproximada da noção de origem, novamente, a ideia não aponta para a sua reprodução genética nem para a produção repetida dos fenômenos. Do mesmo modo, o conhecimento da arte ou dos fenômenos, para Benjamin, não apela por um reunião dos particulares em um contínuo, ou um grupo extenso. A ideia, enquanto paradigma do conhecimento nesse texto, tem a temporalidade da origem [Ursprung], isso é, a temporalidade intensiva, pertencendo à história de modo a-temporal: inaugural, criativo, mas também terminante, final.

A origem, portanto, não se destaca dos dados factuais, mas tem a ver com a sua pré e pós-história. Na dialética inerente à origem encontra a observação filosófica o registro das suas linhas mestras. Nessa dialética, e em tudo o que é essencial,

26 Idem, ibidem,. p.34.

27 Idem, ibidem, p. 34 .

28 Idem, ibidem, p.36. 
a unicidade e a repetição surgem condicionando-se mutuamente. A categoria de origem não é, assim, como quer Cohen, puramente lógica, mas histórica ${ }^{29}$.

Como Benjamin exprimirá em carta a Florens Christian Rang, de 9 de dezembro de 1923: “As ideias são as estrelas em oposição ao sol da revelação. Elas não brilham no grande dia da história, elas não se tratam nele senão de maneira invisível. Elas não brilham senão na noite da natureza30”. A ideia, tal como o nome, pertencerá á história do modo que Benjamin chama de intensivo, ligado à interpretação, o que insere um paradoxo na sua compreensão que deve apelar por aquele ponto de vista duplo: se a noção de tradução, em Benjamin, aponta a tarefa do filósofo para a compreensão da vida em seu desdobramento histórico, a contemplação da ideia ou a rememoração do nome, no Prefácio, apontará para o sentido inverso: a necessidade de inteligir as bordas da história na qualidade de vida natural, como aquilo mesmo que excede a vida na história. Nessa exceção natural à história, Benjamin repete o gesto de sobrepor a linguagem em geral à linguagem humana, extrapolando as bordas da linguagem nomeadora em prol de uma linguagem muda. A contemplação oblíqua da ideia é nisso o desenvolvimento do ato de nomeação exposto no ensaio de 1916: excedendo o som, a linguagem vem do que é mudo somente para voltar-se à sonoridade na tradução. Analogamente, a ideia benjaminiana habita a noite da revelação, "não espera o dia do julgamento final ${ }^{31}$ ”: excede a vida histórica pertencendo e não pertencendo a ela.

A ideia brilha, portanto, na dimensão que excede o tempo, o duplo da vida histórica dos fenômenos: como vida natural, dizer que a ideia é anterior e posterior à vida histórica, significa dar a ideia uma tangência histórica fugidia, semelhante a uma imagem usada por Benjamin em um outro texto seu de juventude, A tarefa do tradutor de 1921, para descrever o movimento da tradução, conceito chave em Benjamin não apenas nessa discussão sobre a linguagem e a nomeação, mas também, como vimos, no tema do conhecimento, e mesmo no tema da sua compreensão dialética da história.

...da mesma forma como a tangente toca a circunferência de maneira fugidia e em um ponto apenas, sendo esse contato e não o ponto, que determina a lei segundo a qual ela continua sua via reta para o infinito, a tradução toca fugaz-

29 Idem, ibidem, p.34.

30 BENJAMIN, 1979, p.294.

31 Idem, ibidem, p. 294. 
mente, e apenas no ponto infinitamente pequeno do sentido do original, para perseguir, segundo a lei da fidelidade, sua própria via no interior da liberdade do movimento da língua ${ }^{2}$.

\section{REFERÊNCIAS BIBLIOGRÁFICAS}

BENJAMIN, Walter. Carta a Gershom Scholem de 11 de novembro de 1916. Carta a Florens Christian Rang de 9 de dezembro de 1923. In: BENJAMIN, W. Correspondance I. Paris: Aubier-Montaigne, 1979, pp.119-121. 293-296.

Prólogo epistemológico-crítico. In: BENJAMIN, W. A origem do drama barroco alemão. $2^{\mathrm{a}}$ edição. Tradução de João Barrento. Belo Horizonte: Autêntica, 2013a, p.13-47. Sobre a linguagem em geral e sobre a linguagem do homem. A tarefa do tradutor. In: BENJAMIN, W.; GAGNEBIN, J. (org.). In: Escritos sobre mito e linguagem. $2^{\mathrm{a}}$ edição. Tradução de Susana Kampff Lages e Ernani Chaves. São Paulo: Duas Cidades; Editora 34, 2013b, p.49-73, 101-118.

CASTRO, C. Benjamin, a tragédia e o trágico. In: OLIVEIRA, L; D’ANGELO, M. (org.). Walter Benjamin: arte e experiência. $1^{\mathrm{a}}$ edição. Rio de Janeiro: Nau; Niterói, RJ: EdUFF, 2009, p.18-37.

HEIDEGGER, Martin. Ser e tempo. $10^{\mathrm{a}}$ edição. Tradução revisada e apresentação de Marcia Sá Cavalcante Schuback, posfácio de Emmanuel Carneiro Leão. Petrópolis, RJ: Vozes; Bragança Paulista, SP: Editora Universitária São Francisco, 2015.

MURICY, K. Alegorias da dialética: imagem e pensamento em Walter Benjamin. $1^{\mathrm{a}}$ edição. Rio de Janeiro: Relume Dumará, 1999 p. 81-154.

PLATÃO. Timeu. In: PLATÃO. Timeu / Crítias. $1^{\text {a }}$ edição. Tradução do grego, introdução e notas de Rodolfo Lopes. Coimbra: Centro de Estudos Clássicos e Humanísticos, 2011. 